\title{
The cognitive behavioural analysis system of psychotherapy prevented recurrence in chronic major depression
}

Klein DN, Santiago NJ, Vivian D, et al. Cognitive-behavioral analysis system of psychotherapy as a maintenance treatment for chronic depression. J Consult Clin Psychol 2004;72:681-8.

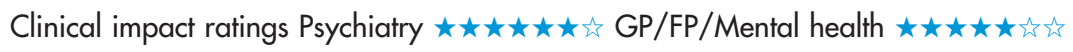

In patients with chronic major depressive disorder (MDD), does the cognitive behavioural analysis system of psychotherapy [CBASP] prevent recurrence?

METHODS

\begin{tabular}{|c|c|}
\hline & Design: randomised controlled trial. \\
\hline & Allocation: $\left\{\right.$ concealed $\left.{ }^{*}\right\}$ t. \\
\hline & Blinding: blinded (\{data collectors\}† and outcome assessors). ${ }^{*}$ \\
\hline & $\begin{array}{l}\text { Follow up period: } 1 \text { year maintenance phase (affer } 12 \text { wks in a } \\
\text { treatment phase and } 16 \text { wks in a continuation phase). }\end{array}$ \\
\hline & Setting: 12 academic centres in the US. \\
\hline & $\begin{array}{l}\text { Patients: } 82 \text { patients who were } 18-75 \text { years of age (mean age } \\
45 \text { y, } 67 \% \text { women); began the treatment phase with a DSM-IV } \\
\text { diagnosis of MDD (duration } \geqslant 2 \text { y) and a score } \geqslant 20 \text { on the } 24 \\
\text { item Hamilton Rating Scale for Depression (HRSD-24); and } \\
\text { responded to CBASP alone during the treatment and continuation } \\
\text { phases. Exclusion criteria included psychotic, bipolar, or } \\
\text { obsessive compulsive disorder; eating disorders in previous year; } \\
\text { substance abuse in previous } 6 \text { months; high risk of suicide; and } \\
\text { serious medical disorders. }\end{array}$ \\
\hline & $\begin{array}{l}\text { Intervention: patients were allocated to CBASP once very } 4 \\
\text { weeks }(n=42) \text { or assessments only }(n=40) \text {. CBASP is highly } \\
\text { structured; teaches social problem solving skills; requires regular } \\
\text { home assignments; and combines techniques borrowed from } \\
\text { cognitive and behavioural approaches, interpersonal } \\
\text { psychotherapy, and psychodynamic psychotherapy. }\end{array}$ \\
\hline $\begin{array}{ll}1 \\
2 \\
2 \\
2\end{array}$ & $\begin{array}{l}\text { Outcomes: time to recurrence (HRSD-24 score } \geqslant 16 \text { on } \geqslant 2 \\
\text { consecutive visits and DSM-IV diagnosis of MDD) and change in } \\
\text { depressive symptoms. }\end{array}$ \\
\hline$\| \vec{c}$ & $\begin{array}{l}\text { Patient follow up: } 74.4 \% \text { completers (all patients included in } \\
\text { survival analysis). }\end{array}$ \\
\hline & $\begin{array}{l}\text { *See glossary. } \\
\text { †Information provided by author. }\end{array}$ \\
\hline
\end{tabular}

\section{MAIN RESULTS}

Fewer patients in the CBASP group than in the control group had a recurrence of $\operatorname{MDD}(2.6 \% \vee 20.9 \%, \log$ rank $\mathrm{p}<0.03)$. When

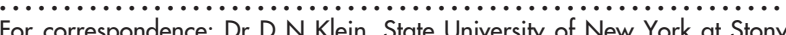
For correspondence: Dr D N Klein, State University of New York at Stony Brook, Stony Brook, NY, USA. dklein@notes.cc.sunysb.edu Source of funding: Bristol-Myers Squibb. recurrence was defined as consensus among a committee of senior investigators that an episode of MDD had occurred, the effect remained $(10.7 \% v 32.0 \%, \mathrm{p}<0.05)$. Over time, depressive symptoms on the HRSD-24 decreased in the CBASP group and increased in the assessments only group $(\mathrm{p}<0.001)$.

\section{CONCLUSION}

In patients who had chronic major depressive disorder and responded to cognitive behavioural analysis system psychotherapy (CBASP), maintenance CBASP once every 4 weeks prevented recurrence.

\section{Commentary}

Tre

he interesting study by Klein et al evaluates the relapse prevention value of a maintenance phase of CBASP following a successful active treatment for 82 chronically depressed patients. What makes this study unique is the exclusive focus on chronic depression. In this study, depression duration averaged $>7$ years for MDD and $>20$ years for dysthymia. It is notoriously difficult to achieve immediate and long-term gains in chronic depression; thus, this ambitious research suggests that maintenance CBASP may reduce relapse in an especially vulnerable population.

Despite the strengths of this study, its generalizability is questionable. Firstly, the sample for the original treatment study was well pruned with only $66 \%$ of those screened being randomised to treatment. In addition to the usual study exclusion criteria (eg, suicidality and psychosis), potential patients were also excluded if they had failed 3 psychotropic treatments, 2 psychosocial treatments, and/or electroconvulsive therapy. Secondly, because the current sample included only those who were both completers and responders to the original CBASP treatment, only a tiny minority of the original sample remained (18\%). These sampling methods cannot show whether maintenance CBASP would help those who initially responded to another treatment or who had only a partial response to CBASP. Furthermore, these findings do not provide clear evidence that more severe or recalcitrant depression would respond to CBASP at all.

This excellent, timely study suggests that psychosocial interventions may enhance maintenance for chronic depression, although results should be cautiously applied to patients dissimilar from this limited sample.

Paula Truax, PhD Pacific University Portland, Oregon, USA

1 Keller MB, McCullough JP, Klein DN, et al. A comparison of nefazodone, the cognitive behavioral-analysis system of psychotherapy, and their combination for the treatment of chronic depression. N Engl J Med 2000;342:1462-70. 